\title{
Reducing the harms of alcohol in the UK
}

\author{
Successful policies have worked elsewhere, so delays in implementing \\ them are costing lives
}

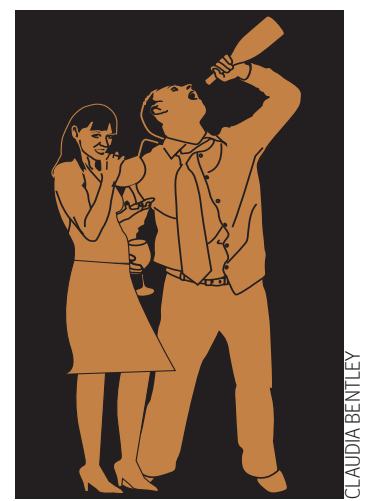

ALTERED STATES, $p 1302$ HISTORY, $p 1310$

Ian Gilmore president of the Royal College of Physicians, ian.gilmore@rcplondon.ac.uk Nick Sheron hepatologist, Medical School, Southampton University Hospital, Southampton S0166YD

Competing interests: $\mathrm{IG}$ is a member of the Alcohol Research and Education Council and chairman of the Alcohol Health Alliance UK. NS is a trustee of Alcohol Concern, the Drinkaware Trust, and honorary secretary of the Alcohol Health Alliance UK.

Provenance and peer review: Commissioned; not externally peer reviewed.

BMJ 2007;335:1271-2 doi:10.1136/bmj.39426.523715.80
Alcohol causes major health problems-the Cabinet Office reported up to 150000 hospital admissions and 15000-22 000 deaths overall in 2003. ${ }^{1}$ Between 1991 and 2005, deaths directly attributed to alcohol almost doubled. ${ }^{2}$ More people are dying from alcohol related causes than from breast cancer, cervical cancer, and infection with methicillin resistant Staphylococcus aureus combined. Furthermore, the recent report from the World Cancer Research fund confirmed that even drinking alcohol within so called "safe limits" increases the risk of cancer of the breast and upper gastrointestinal tract. ${ }^{3}$

The cultural and sociological factors that determine our patterns of drinking may date back thousands of years. ${ }^{4}$ As such, the Licensing Act 2005 was always unlikely to transform the culture of feast drinking to that of a Mediterranean society. Similarly, other options to reduce harm favoured by government and the alcohol industry-education and public information-don't seem to change drinking behaviour or to reduce alcohol related harm. ${ }^{5}{ }^{6}$ So, can we justify trying tougher measures to reduce alcohol related harmparticularly to health-and is there any evidence to show they would work?

The turning point in a similar debate over tobacco control was the effect of passive smoking, yet damage to third parties from exposure to alcohol misuse is far greater. Drinking alcohol is a factor in more than half of violent crimes and a third of domestic violence. Between 780000 and 1.3 million children are affected by their parents' use of alcohol-30-60\% of child protection cases and $23 \%$ of calls to the National Society for the Prevention of Cruelty to Children about child abuse or child neglect involved drunken adults. ${ }^{1}$ This seems justification enough for society to debate what reasonable and evidence based means could reduce the harm caused by alcohol.

Evidence on alcohol policy has been expertly reviewed for the Academy of Medical Sciences, ${ }^{7}$ the European Commission, ${ }^{8}$ and the World Health Organization (WHO). ${ }^{9}$ The findings were similar in each case-effective measures included increasing prices, controlling alcohol advertising, increasing the minimum age for buying alcohol, and restricting opportunities to buy alcohol. Others were specific measures to reduce drink driving, including lowering maximum blood alcohol concentrations to $0.5 \mathrm{~g} / 1$ and increasing enforcement with random breath testing of drivers. Some of these specific measures have knockon effects; French campaigns to enforce drink driving laws reduced wine consumption in restaurants by around $15 \%,{ }^{7}$ and a combination of lower alcohol limits for drivers and vigorous enforcement in Australia showed wider health benefits. ${ }^{8}$

Modelling of these measures by WHO has shown that increasing the price of alcohol is the most effective and cost effective measure. ${ }^{9}$ Like any commodity the purchase of alcohol is price sensitive. Increasing prices has the biggest effect on the heaviest consumers and on young people, who spend a relatively high proportion of their income on alcohol. ${ }^{7}$ Between 1980 and 2003 the price of alcohol increased 24\% more than prices generally, but disposable income increased by $91 \%$, making alcohol $54 \%$ more affordable in 2003 than in $1980 .{ }^{10}$ Models from the UK treasury show that up to $50 \%$ more tax on spirits would increase government income even though cross border smuggling would probably increase, and taxation could be increased even more for wine and beer before income to the treasury would be reduced. ${ }^{11}$ To suggest, as producers and retailers do, that increasing the price of alcohol would not reduce alcohol related harm goes against the evidence and the fundamental principles of marketing-product, price, promotion, and place.

Early detection and intervention are almost as effective at reducing harm to health but require specific funding. ${ }^{9}$ The Department of Health in England has funded a large ongoing study of early detection and brief intervention in three settings-primary care, emergency departments, and prisons. If this confirms the results of previous studies, ${ }^{12}$ early intervention should be implemented more widely and funded properly. Banning advertising of alcohol and reducing its availability are also effective, although less so than increasing taxation and early intervention, as has been the case with smoking. ${ }^{13}$

Perhaps the most striking and convincing recent evidence that reducing harmful drinking saves lives comes from Russia. After Mikhail Gorbachev introduced his polices on alcohol control, deaths (half of which were caused by accidents, violence, and poisoning) dropped dramatically, and 1.2 million lives were saved. ${ }^{14}$ How many more lives will be damaged by alcohol in the UK before our governments decide to tackle the problem with measures that are likely to work? 
1 Prime Minister's Strategy Unit. Alcohol misuse. Interim analytical report. London: Prime Minister's Strategy Unit, 2003. www.cabinetoffice.gov. uk/strategy/work_areas/alcohol_misuse/interim.aspx.

2 National Statistics. News release. Alcohol-related death rates almost double since 1991. 2006. www.statistics.gov.uk/pdfdir/ aldeaths1106.pdf.

3 World Cancer Research Fund. Food, nutrition, physical activity and the prevention of cancer: a global perspective. London: WCRF, 2007.

4 Engs RC. Do traditional western European drinking practices have origins in antiquity? Addiction Res 1995;2:227-39.

5 Babor TF, Caetano R, Casswell S, Edwards G, Giesbrecht N, Graham K, et al. Alcohol: no ordinary commodity-research and public policy. Oxford: Oxford University Press, 2003.

6 National Institute for Health and Clinical Excellence. School-based interventions on alcohol. 2007. www.nice.org.uk/nicemedia/pdf/ AlcoholSchoolsDraftScope.pdf.

7 Academy of Medical Sciences. Calling time. The nation's drinking as a major health issue. London: AMS, 2004. www.acmedsci.ac.uk/index.

8 Anderson P, Baumberg B. Alcohol in Europe: a public health perspective. EU Health and Consumer Protection Directorate General. 2007.
9 Chisholm D, Rehm J, Van OM, Monteiro M. Reducing the global burden of hazardous alcohol use: a comparative cost-effectiveness analysis. I Stud Alcohol 2004;65:782-93.

10 Institute of Alcohol Studies. Alcohol, price, legal availability and expenditure. 2007. IAS factsheet. www.ias.org.uk/resources/ factsheets/price availability.pdf.

11 Huang CD. Econometric models of alcohol demand in the United Kingdom. Government Economic Service Working Paper 2003;140:1-51.

12 Bertholet N, Daeppen JB, Wietlisbach V, Fleming M, Burnand B. Reduction of alcohol consumption by brief alcohol intervention in primary care: systematic review and meta-analysis. Arch Intern Med 2005;165:986-95.

13 The Impact of Alcohol Advertising. ELSA project report on the evidence to strengthen regulation to protect young people. Peter Anderson on behalf of the National Federation for Alcohol Prevention, the Netherlands, and the ELSA project 2005-2007. http://www.stap.nl/elsa/elsa_project.

14 Nemtsov AV. Alcohol-related human losses in Russia in the 1980s and 1990s. Addiction 2002;97:1413-25.

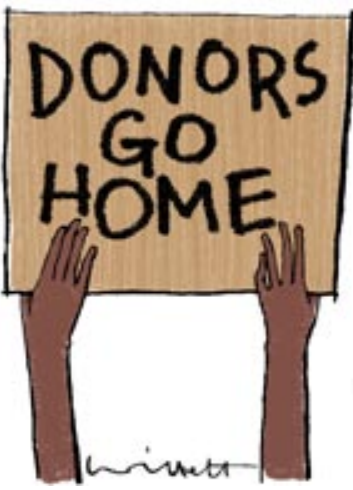

Dan J Ncayiyana emeritus vice chancellor and professor, Durban Institute of Technology, Durban 4000, South Africa danjn@telkomsa.net Competing interests: None declared. Provenance and peer review: Commissioned; not externally peer reviewed.

BMJ 2007;335:1272-3 doi: $10.1136 /$ bmi.39420.432951.80
Poverty is acknowledged to be the biggest risk for ill health worldwide. The World Health Organization estimates that about 1.2 billion people live in extreme poverty, without decent shelter, clean water, adequate sanitation, or sufficient food. ${ }^{1}$ The response of the rich nations to global poverty has been to wave the magic wand of development aid, also known as "official development assistance," which distinguishes it from ad hoc assistance for emergencies such as natural disasters. Development aid is meant to help eradicate poverty through the stimulation of economic growth.

A total of $\$ 2.3$ trillion ( $£ 1.1$ trillion; $€ 1.6$ trillion) has been spent on development aid over the past five decades, and it has been the subject of vigorous debate among development economists. Three books have emerged on the subject in the past two years-The Bottom Billion by Paul Collier, The White Man's Burden by William Easterly, and The End of Poverty by Jeffrey Sacks. ${ }^{2-4}$ While each takes a different view of development aid, all share former US Treasury Secretary Paul O'Neal's sigh of exasperation that, "We've spent trillions of dollars on these problems and we have damn near nothing to show for it." Development aid has done next to nothing to help grow national economies or to lift people out of extreme poverty.

Collier blames the poverty stricken countries of the bottom billion of the world's six billion population themselves for "falling behind and often falling apart, [who] co-exist with the twenty-first century, but [whose] reality is the fourteenth century: civil war, plague and ignorance." He believes that for aid to be effective, these situations will need to be dealt with through national political reform, or even external intervention. Sachs disagrees and argues that the amount of money given in development aid is too small to have an effect. In 2002, development aid amounted to \$30 for each sub-Saharan African; $\$ 18$ of this sum was spent on donor country consultants, food aid, and debt repayments, leaving only $\$ 14$ for direct aid.

Easterly contends that the entire aid set-up is fatally flawed, as donors largely lack evidence based knowledge of the situation on the ground in poor countries, or of how to make aid effective. The crux of the problem, he argues, is that "The status quo-large international bureaucracies giving aid to large national government bureaucracies-is not getting money to the poor." Consequently, the poor are not getting the vaccines, the antibiotics, the bed nets, the doctors, or the nurses they need to improve their health. Tumwine observed in a recent $B M J$ editorial that "expenditure on health has not improved substantially in poor countries, and hospital wards in these countries are best described as pathetic." ${ }^{5}$

\section{Self interest rules}

Some critical observations on development aid merit attention. Although aid is often equated with charity, in reality it is more about the political and economic self interest of the giver, with much of it being tied to the purchase of goods (including military ware) and services from the donor country. ${ }^{6}$ Development aid buys influence, with French and British aid largely going to their former colonies, and that of the US to Israel and Egypt. Development aid has not lived up to its promise of unleashing economic growth and, ironically, countries that have registered the most robust growth in recent years-such as India, China, and Botswanawere recipients of the least aid, and vice versa.

So, what should be done about development aid? Firstly, we must scrap the idea that development aid-as presently structured-is the best way to eradicate poverty. Development is a long term process that may not benefit the poor for generations. Poverty remains an enduring feature of life in India, China, and Botswana despite spectacular growth rates. Development is best achieved through national initiatives and good governance, coupled with equitable international trade arrangements 
(something the wealthy nations refuse to do at the World Trade Organization).

The needs of the poor are immediate and cry out for direct and urgent intervention now. International aid genuinely earmarked for eradicating poverty must be taken out of the hands of the politicians and bureaucracies of both donor countries and recipient countries. Such funds should be controlled by independent and accountable agencies, which have knowledge of the existing needs and have direct access to those in need. Aid must be contingent upon the accountability of those who administer it, feedback from those who benefit from it, and measurable or otherwise verifiable outcomes.

Oxfam International-a confederation of 13 organisations working together with over 3000 partners in more than 100 countries to find lasting solutions to poverty and injustice-is a good example of an agency not indentured to political patronage. ${ }^{7}$ Oxfam has a deep understanding of the complexities underpinning poverty, and it works for and with the poor to provide them with relief aid and to empower them to help themselves. Above all, Oxfam is able to "speak truth to power" in its advocacy for the poor.

Rich countries may still wish to coddle dictators and other regimes-malevolent or otherwise-with handouts intended to influence solidarity or security; just don't call it development aid.

1 WHO. Health and development: poverty and health. www.who. int/hdp/poverty/en/.

2 Collier P. The bottom billion. New York: Oxford University Press, 2007.

3 Easterly W. The white man's burden. Oxford: Oxford University Press, 2006.

4 Sachs I. The end of poverty. London: Penguin Books, 2005.

5 Tumwine J. Equitable access to health care. BMJ 2007;335:833-4.

6 Nelson EAS. Development aid: the way forward. BMJ 1994;481-2.

7 Oxfam International. United for a more equitable world. www. oxfam.org.

\section{Web 3.0 and medicine}

\section{Make way for the semantic web}

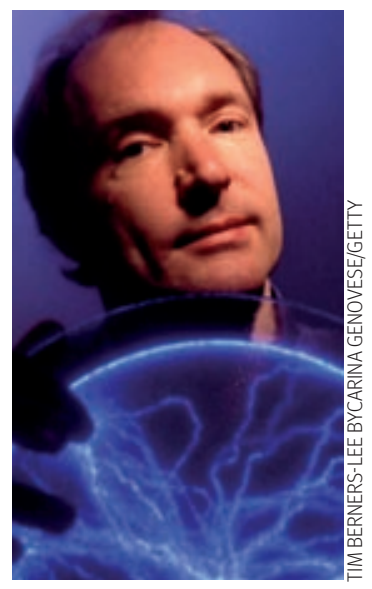

This time last Christmas, medical blogs and RSS feeds were the hot technology topics, and we were debating the merits of newer models of scholarly publishing in web 2.0, such as open access and medical wikis. ${ }^{1}$ Can web 3.0 be here already?

Recently, a neurologist devised an apt medical metaphor for web 3.0. He suggested that, "The development of the graphical web from its early days in 1995 to the social web of late 2007 is comparable to the developing brain." He went on to say that, "Whereas web 1.0 and 2.0 were embryonic, formative technologies, web 3.0 promises to be a more mature web where better 'pathways' for information retrieval will be created, and a greater capacity for cognitive processing of information will be built." (Personal communication, A Wong, 2007.)

So what is web 3.0, and why is it called the semantic Dean Giustini UBC biomedical
branch librarian, Diamond web (table)? Although both terms are used interchangeHealthcare Centre and Vancouver Hospital, BC, Canada V5Z 1M9 dean.giustini@ubc.ca Competing interests: None declared.

Provenance and peer review: Commissioned; not externally peer reviewed.

BMJ 2007;335:1273-4 doi: 10.1136/bmj.39428.494236.BE ably, they convey slightly different, if complementary, views of the new web. The web 3.0 label is often used as a marketing ploy for "the next big thing." An important feature of web 3.0 is that it enables computers to talk to each other so that they can perform the tasks necessary for us to do our work. However, a primary feature of web 3.0 is that it uses metadata-data about data. This will transform the web into a giant database, and organise it along the lines of PubMed, or one of our trusted medical library catalogues. ${ }^{2}$

Somehow, the term semantic web has escaped the reproach of web 3.0, perhaps because it was coined by the respected web expert Sir Tim Berners-Lee in his landmark paper in Scientific American. ${ }^{3}$ His ideas continue to have tremendous salience. Berners-Lee's view is that we need to use semantic annotation to express the meaning latent in web documents, by drawing out inferences in documents deep within the web. As a pioneer in search technology, and director of the World Wide Web Consortium, Berners-Lee main- tains that access to a global "web of data"-what weaves the entire web together into a coherent whole-should help to solve humankind's most complex problems. ${ }^{4}$

To understand why we need web 3.0, let's examine the current state of the web. Currently, access to endless reams of unorganised information in web 2.0 shifts the online habits of doctors to searching, not finding. Consequently, medical librarians believe that it is necessary to build better mechanisms for information retrieval. ${ }^{5}{ }^{6}$ As a colleague said to me recently, "we need find engines, not search engines."

\section{The problem with search results}

In medicine, finding the best evidence has become increasingly difficult, even for librarians. Despite its constant accessibility, Google's search results are emblematic of an approaching crisis with information overload, and this is duplicated by Yahoo and other search engines. Consequently, medical librarians are leading doctors back to trusted sources, such as PubMed, Clinical

At a glance: Comparison of the features of web 2.0 and 3.0

\begin{tabular}{ll} 
Web 2.0 & Web 3.0 \\
"The document web" & "The data web" \\
\hline Abundance of information & Control of information \\
\hline Controversial & No less controversial \\
\hline “The social web" & "The intelligent web" \\
\hline The second decade, 2000-9 & The third decade, 2010-20 \\
\hline Google as catalyst & $\begin{array}{l}\text { Semantic web companies as } \\
\text { catalyst }\end{array}$ \\
\hline Wisdom of the crowds & Wisdom of the expert \\
\hline Mashups, fragmentation integration, & \\
\hline new tools & Why search, when you can find? \\
\hline Search, search, search & Ontologies, semantic systems \\
\hline Google's Pagerank algorithm & Standards, protocols, rules \\
\hline Lawless, anarchic & Digital above all else \\
\hline Print and digital & \\
\hline
\end{tabular}




\section{Glossary}

Data mining-a process of knowledge discovery or retrieval of hidden information from data banks and clusters of databases

Mashup-a web application or site that mixes content from multiple sources

Medical wiki-a website or similar online resource that allows users to add and edit medical information collectively RSS (really simple syndication)-a format for sharing content between different websites

Semantic web-a project that intends to create a universal medium for information exchange from 2008 and beyond by putting documents with computer processable meaning (semantics) on the world wide web

Social tagging-the application of freely chosen labels, or tags, to web documents, web pages, and photo sharing sites, such as www.flickr.com

Web 3.0-a term used to describe the evolution of the web, and our responses to it, in finding and organising new information

Evidence, and the Cochrane Library, and even taking them to their library bookshelves instead. Unless better channels of information are created in web 3.0, we can expect the information glut to continue.

Web 3.0 is likely to have a big effect on medicine in 2008. In bioinformatics, it will become more common to process ever larger amounts of data. In fact, experts in bioinformatics already search for data from disparate systems, and they have started to build rich semantic relations into information tools for knowledge discovery. Finally, greater capacity for creating knowledge in medicine will be possible if we have the will to publish clinical data openly and transparently, and subject it to scrutiny.

Developing a more personalised healthcare system will be an important challenge for doctors in web 3.0. In an era of greater personalisation, treating patients' health problems according to their genetic profiles will depend on using the latest information technologies. ${ }^{8}$ Even the treatment of new diseases and warning systems for natural disasters will benefit from the merging of epidemiological datasets with virtual, three dimensional tools like Google Earth. Making the search for health information efficient and responsive to patients' needs will also help reduce the costs of medical treatment.

\section{Knowledge creation}

Social software enthusiasts may well find that the new web will be fertile ground for the creation of knowledge. Although already popular, wikis may well serve as platforms for the exploration of web 3.0. One innovative wiki-Wikiproteins-is already using semantic technologies. In contrast to other wikis, Wikiproteins imports data mined from several of the world's leading biomedical databases, such as PubMed, UniProt, and the National Library of Medicine. Its integrated entries are a useful combination of genetic information and scientific literature. Notably, the confluence of databases in Wikiproteins yields more than two million factual associations for data mining and over five billion associated pairs. ${ }^{9}$

Each new version of the web should be a better iteration of its predecessor, and web 3.0 should be no exception. In medicine, we should focus on the ability to locate trusted clinical information, while creating the means to produce new knowledge. Information retrieval in web 3.0 should be based less on keywords than on intelligent ontological frameworks, such as the National Library of Medicine's Unified Medical Language System, Medline's trusted MeSH vocabulary, or some other tool.

The National Library of Medicine is working on automated indexing, which may be part of the solution for searching the biomedical web. ${ }^{10}$ Finally, as we move further into the digital age, our trusted print libraries must continue to be well funded and should not be forgotten in the midst of the intelligent web.

The question of whether http://del.icio.us and www. connotea.org-two popular social tagging sites-will be useful in web 3.0 remains doubtful. ${ }^{11}$ Social tagging or "indexing" has limitations because of poor controls of synonyms, homonyms, spelling conventions, and other linguistic variations. Think about the myriad ways we describe a heart attack; these variations have enormous implications for searching and require control to optimise retrieval.

A smarter medical web is coming. Its two most exciting features will be the better organisation of documents and a deeper use of the knowledge base in medicine. In terms of searching, the semantic web should resemble a library catalogue, where documents are described and given meaningful access points for easy retrieval. However, in getting to web 3.0, let's aim for something better than the current web, not the incoherent mess of web 2.0. Logically, web 3.0 should bring order to the 21 st century web in the same way that Dr John Shaw Billings's Index Medicus brought order to medical research back in the 19th century. ${ }^{12}$ As a medical librarian, I sincerely hope that web 3.0 will return us to some of the time honoured principles of my profession.

1 Giustini D. How web 2.0 is changing medicine. BM/ 2006;333:1283-4.

2 Cho A, Giustini D. The semantic web as a large searchable catalogue: a librarian's perspective. Semantic Report. 2007. www. semanticreport.com/index.php?option=com content\&task=vie w\&id $=52$ \&ltemid $=79$.

3 Berners-Lee T, Hendler J, Lassila 0. The semantic web. a new form of web content that is meaningful to computers will unleash a revolution of new possibilities. SciAm 2001 www.sciam.com/article. cfm?articleID=00048144-10D2-1C70-84A9809EC588EF21.

4 World Wide Web Consortium. Semantic Web Health Care and Life Sciences Interest Group. 2007. www.w3.org/2001/sw/hcls/.

5 Robu I, Robu V, Thirion B. An introduction to the semantic web for health sciences librarians. J Med Libr Assoc 2006;94:198-205.

6 Lorence DP, SpinkA. Semantics and the medical web: a review of the barriers and breakthroughs in effective healthcare query. Health Info Libr/2004;21:109-16.

7 WillinskyJ, Murray S, Kendall C, Palepu A. Doing medical journals differently: open medicine, open access and academic freedom. Can J Commun 2007. http://pkp.sfu.ca/node/776.

8 Cho A, Giustini D. Back to the future: viewing health librarianship through the semantic lens of web 3.0. Canadian Health Libraries association (in press).

9 Mesko B. Web 3.0 and medicine. ScienceRoll blog. 2007. http:// scienceroll.com/2007/04/06/web-30-and-medicine/.

10 Aronson AR, Bodenreider O, Chang HF. The NLM indexing initiative. ProcAMIA Symp 2007:17-21

11 Kamel Boulos MN, Wheeler S. The emerging web 2.0 social software: an enabling suite of sociable technologies in health and health care education. Health Info Libr J 2007;24:2-23.

12 Lyndenberg HM. John Shaw Billings: creator of the National Medical Library, and its catalogue. Chicago: American Library Association, 1924. 